\title{
Examining the factors influencing leaf disease intensity of Kalopanax septemlobus (Thunb. ex Murray) Koidzumi (Araliaceae) over multiple spatial scales: from the individual, forest stand, to the regions in the Japanese Archipelago
}

\author{
Shota Sakaguchi ${ }^{1, *}$, Michimasa Yamasaki ${ }^{1}$, Chihiro Tanaka $^{2}$ and Yuji Isagi ${ }^{1}$ \\ ${ }^{1}$ Laboratory of Forest Biology, Division of Forest and Biomaterials Science, Graduate School of Agriculture, Kyoto University, \\ Kyoto 6068502, Japan \\ ${ }^{2}$ Laboratory of Terrestrial Microbial Ecology, Division of Environmental Science and Technology, Graduate School of Agriculture, \\ Kyoto University, Kyoto 6068502, Japan
}

\begin{abstract}
We investigated leaf disease intensity of Kalopanax septemlobus (prickly castor oil tree) caused by the parasitic fungus Mycosphaerella acanthopanacis, in thirty natural host populations in the Japanese Archipelago. The disease intensity observed for individual trees were analyzed using a generalized additive model as a function of tree size, tree density, climatic terms and spatial trend surface. Individual tree size and conspecific tree density were shown to have significant negative and positive effects on disease intensity, respectively. The findings suggest that the probability of disease infection is partly determined by dispersal of infection agents (ascospores) from the fallen leaves on the ground, which can be enhanced by aggregation of host trees in a forest stand. Regional-scale spatial bias was also present in disease intensity; the populations in northern Japan and southern Kyushu were more severely infected by the fungus than those in southwestern Honshu and Shikoku. Regional variation of disease intensity was explained by both climatic factors and a trend surface term, with a latitudinal cline detected, which increases towards the north. Further research should be conducted in order to understand all of the factors generating the latitudinal cline detected in this study.
\end{abstract}

Key words: castor aralia, host density, interspecific interaction, leaf disease, tree size

\section{INTRODUCTION}

It has been recognized that an accurate understanding of plant-pathogen interaction requires a broad scope of investigation (Burdon and Thrall 2000, Holdenrieder et al. 2004, Moore and Borer 2012), however, fine-scale studies have often dominated forest pathology. At the forest stand scale, key processes connecting the interaction include pathogen dispersal interacting with the spatial patterns of host tree distribution, which can be influenced by land- scape structure and biotic factors. Across a region, the spatial distribution of different genotypes of a pathogen and/or host tree can account for the variation in related tree mortality (e.g., McLaughlin 2001), which highlights the temporal and spatial pervasiveness of interacting antagonistic species under geographically differing environmental combinations. Therefore, elucidation of spatially explicit disease intensity at a coarse, regional scale con-

\section{Open Access http://dx.doi.org/10.5141/JEFB.2012.032}

This is an Open Access article distributed under the terms of the Creative Commons Attribution Non-Commercial License (http://creativecommons. org/licenses/by-nc/3.0/) which permits unrestricted non-commercial use distribution, and reproduction in any medium, provided the original work is properly cited.
Received 28 June 2012, Accepted 10 September 2012

*Corresponding Author

E-mail: sakaguci@kais.kyoto-u.ac.jp Tel: +81-75-753-6129 


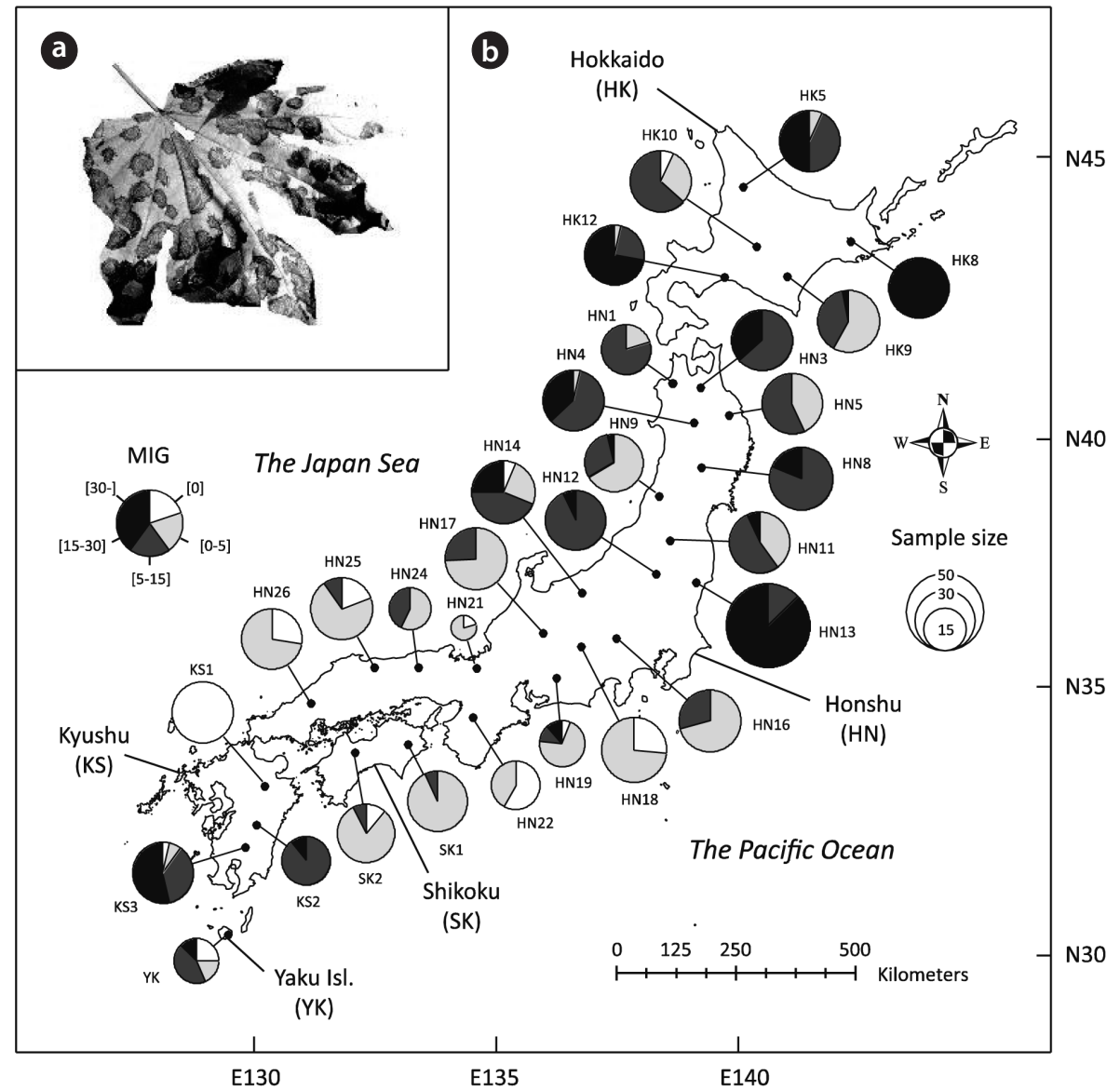

Fig. 1. (a) Leaf spot disease of Kalopanax septemlobus caused by Mycosphaerella acanthopanacis. (b) Locations of the 30 populations of K. septemlobus examined in this study. Mean infection grade in 5 classes of individual trees are superimposed in pie-charts for each population, where circle size is proportional to sample size. More information of these populations are available in the supplementary material and in Sakaguchi et al. (2011) by referring the corresponding population codes.

tributes increasingly to our understanding of ecological and evolutionary processes in plant-pathogen interaction (Manel et al. 2003, Thompson 2005).

A temperate deciduous tree, Kalopanax septemlobus (Thunb. ex Murray) Koidzumi (Araliaceae) is the sole representative of the genus Kalopanax endemic to East Asia (Ohashi 1994, Ohba 1999, Xiang and Lowry 2007). It can be found as a typical sparsely distributed tree species in mesic temperate forests (Sakaguchi et al. 2010) in the Japanese Archipelago, the Korean Peninsula and China. The leaves of K. septemlobus can be infected by Mycosphaerella acanthopanacis Sydow et Hara (Mycosphaerellaceae), an ascomycetous fungus which causes leaf spot disease on the living leaves (Sakamoto 1994). The ascospores of the fungus are discharged from late spring to early summer from the ascomata formed on the fallen leaves of K. septemlobus on the forest floor (Sakamoto 1994), and are thought to be blown by wind colonizing living leaves.
The leaves infected by this fungus exhibit light- to darkbrown zonate leaf spots (Fig. 1a), which can grow to over $3.0 \mathrm{~cm}$ in diameter in autumn (Sakaguchi personal observation). On the infected leaves, the spermagonia of M. acanthopanacis are formed during September to April (Sakamoto 1994), completing its life cycle. The K. septemlobus trees which are intensively damaged by the disease shed almost all of their leaves by mid-September (Fujimori et al. 2006). The intensity of the leaf disease varies among individual trees within a forest stand, and shows a negative correlation with decreasing intraspecific tree density (Fujimori et al. 2006). Also, the seedling mortality of $K$. septemlobus increases with increasing proximity to conspecific adult trees, which is suggested to be caused by leaf damage due to M. acanthopanacis infection (Fujimori 2007), indicating that the leaf disease is an important selective force throughout the life cycle of K. septemlobus, limiting tree density in forest stand (Fujimori et 
al. 2006). However, it is largely unknown whether other K. septemlobus populations are infected by leaf spot disease at the same rate as those observed by Fujimori et al. (2006), although it is of particular importance to elucidate the inter-population variation in the disease intensity on a larger spatial scale, in order to understand the evolutionary aspects of plant-fungus interaction.

Because of the wide distribution range of K. septemlobus and relative ease in evaluating the disease intensity in an individual tree, it is a suitable system for examination of the variation in leaf disease intensity at different spatial scales. In this study, we investigated the leaf disease intensity of $K$. septemlobus caused by the parasitic fungus $M$. acanthopanacis in thirty natural host populations in the Japanese Archipelago. We then statistically assessed whether there is a regional spatial bias in disease intensity, with other factors, including local host density, tree size and abiotic environment factors, being assessed as covariates. This is the first field study reporting the existence of spatial bias in leaf disease intensity caused by plant pathogen at the archipelago scale.

\section{MATERIALS AND METHODS}

\section{Field survey}

From late September to late October in 2007 (Appendix 1), when the size of leaf spot is nearly at its maximum (Sakamoto 1994), we investigated leaf disease intensity for 827 individual trees in 30 natural populations ( $27.6 \pm 8.7$ trees per population; mean $\pm \mathrm{SD}$ ) of $K$. septemlobus across its distribution range in Japan (Fig. 1b). To quantatively evaluate the disease intensity of each tree, we employed an index of mean infection grade (MIG) defined for this leaf disease by Fujimori et al. (2006). Thirty leaves were randomly selected from the uppermost canopy of the trees, inspected from the ground using binoculars $(\times 8)$, and classified according to five grades that represented the disease intensity of individual leaves. The grades were defined according to the proportion of brown-spotted area on leaves: 1) $0 \%$, 2) $1-25 \%$, 3) $26-50 \%$, 4) $51-75 \%$, and 5) $76-100 \%$. The MIG index was then calculated for each tree using the following equation:

$$
\begin{aligned}
\text { MIG }= & \left(12.5 N_{2}+37.5 N_{3}+62.5 N_{4}+87.5 N_{5}\right) / \\
& \left(N_{1}+N_{2}+N_{3}+N_{4}+N_{5}\right)
\end{aligned}
$$

Where $N_{1}, N_{2}, N_{3}, N_{4}$ and $N_{5}$ are the number of leaves classified into grades $1-5$, respectively. We employed the in- dex of MIG in the field survey, because 1) it is relatively easy to observe the uppermost canopy layer of K. septemlobus and 2) the leaf disease caused by M. acanthopanacis is particularly distinguishable owing to its large spot with clear boundary (Ito 1973, Sakamoto 1994). Stem diameter was also measured, and geographic location of each tree recorded using a GPS (GPSMAP 60CSx; Garmin, Olathe, KS, USA). To evaluate local host density, we counted the number of conspecific trees within a distance of $20 \mathrm{~m}$ from the location of each tree.

\section{Statistical analysis}

The MIG index was arcsin-transformed to obtain closer approximation to normality, and was analyzed using a generalized additive model (GAM) with a Gaussian error distribution. We considered five fixed terms in the model as 1) tree basal area $\left.\left(\mathrm{cm}^{2}\right), 2\right)$ the number of conspecific trees within a distance of $20 \mathrm{~m}$ (tree density), 3) annual mean temperature $\left.\left({ }^{\circ} \mathrm{C}\right), 4\right)$ precipitation of spring quarter (mm)(from April to June) and 5) a spatial surface factor which was calculated from the geographic components. Annual mean temperature and monthly precipitation were extracted from 1-km mesh climate normals (Japan Meteorological Agency). Non-linear relationships between response and independent variables were assumed for all terms. Complexity of smoothing functions was controlled by a fixed number of degrees of freedom with $k=5$ for the spatial trend surface and $k=3$ for the other terms in avoidance to surface overfitting. We used R-package mgcv 1.7-0 by Wood (2010) in R 2.12.0 (R Development Core Team 2010, http://www.r-project.org) to obtain parameter estimates.

\section{RESULTS AND DISCUSSION}

Visual inspection suggested large-scale spatial bias in the observed MIG (Fig. 1b). While most individuals were scored a MIG lower than 5 in the populations of southern Honshu, Shikoku and northern Kyushu, the populations in Hokkaido and the northern Honshu showed higher MIG values, some of which included severely infected individuals with MIG scores of over 30 (e.g., HK8 and HN13). In addition, the populations in southern Kyushu and Yaku Island tended to exhibit larger MIG.

All five terms considered in the GAM model were shown to have significant effects on MIG (Fig. 2). Variation in the MIG of individual trees was partly explained by the factors influencing at local spatial scales. First, tree 

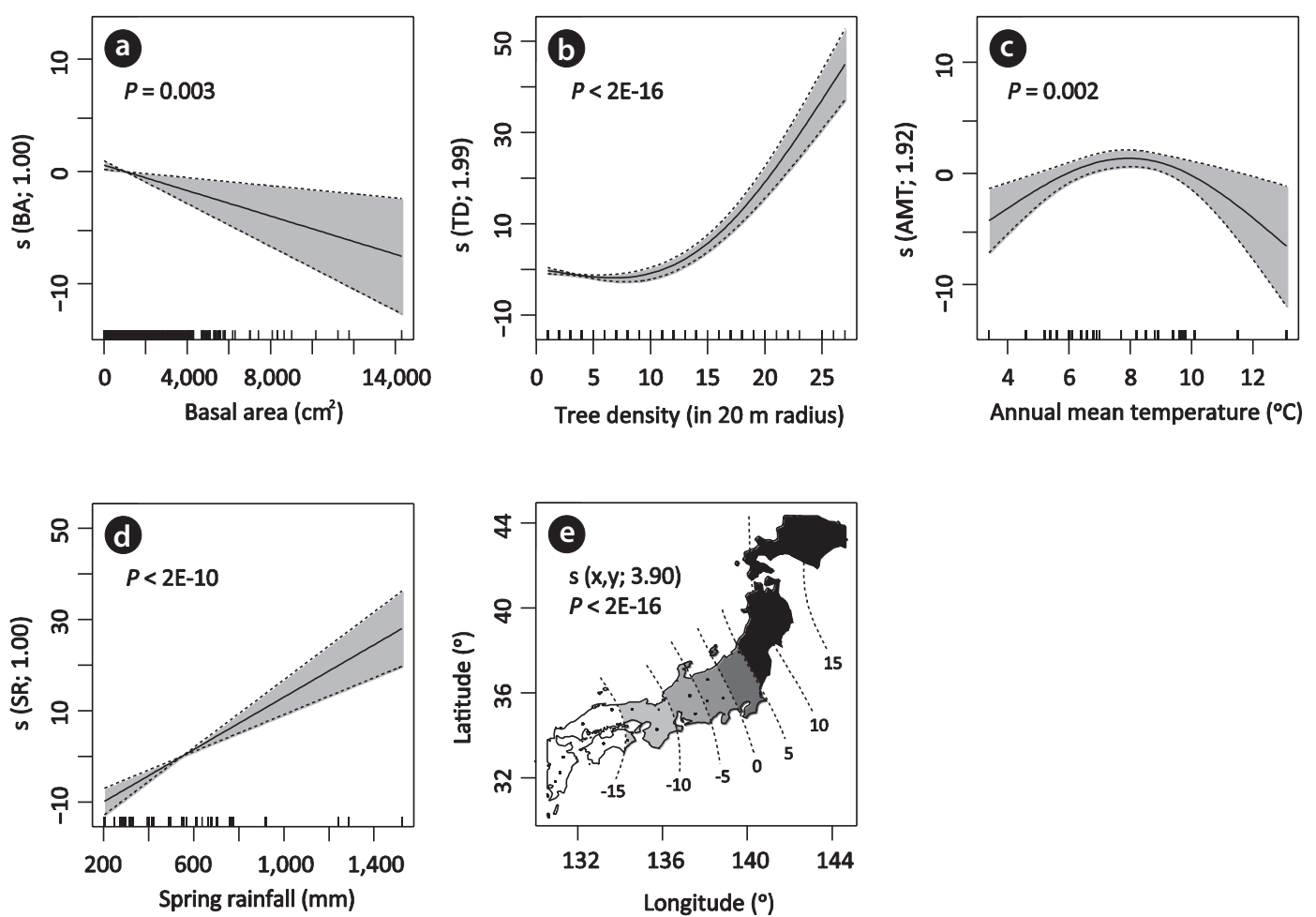

Fig. 2. The effects of (a) basal area (BA) of a tree, (b) conspecific tree density (TD), (c) annual mean temperature (AMT), (d) spring rainfall (SR; from April to June) on the mean infection grade of Kalopanax septemlobus trees. Each panel shows the partial effect of predictors, expressed as fitted smooth functions with $95 \%$ boot-strapped confidence intervals (dashed lines). Fitted function is indicated as s (names of the predictor, estimated degrees of freedom). Ticks in the X-axis represent the location of observations along the predictor. Spatial trend surface estimated against longitude/latitude space is shown in (e).

basal area was shown to have a negative effect on MIG $(P=0.003, d f=1.00)$ (Fig. 2a). The infection of M. acanthopanacis is carried out via ascospores dispersed from fallen leaves on the ground, and the leaves at the lower part of the living plant start to show earlier spot expansion leading to defoliation (Sakamoto 1994). Thus, it is likely that ascospore density or probability of infection would be higher at the lower layer in a forest, which exposes individuals with smaller basal areas to higher infection risks. A similar pattern has been reported from the cooltemperate tree species Swida controversa (Hemsl.) Sojak (Cornaceae), where local density controls heterogeneous defoliation due to the infection agent 'zonate leaf blight' (Osono et al. 2004). Secondly, this study confirmed that the MIG of $K$. septemlobus was dependent on conspecific tree density $(P<2 \mathrm{E}-16, d f=1.99)$ (Fig. 2b), as detected by Fujimori et al. (2006). The finding suggests that aggregation of individual trees would allow the infection agents to be more easily transmitted among individuals at the forest stand scale. There are accumulated evidences which show that host density can be an important predictor of tree seedling mortality and plant growth (Burdon and
Chilvers 1982, Gilbert et al. 1994, Gilbert 2002, Yamazaki et al. 2009, Nossov et al. 2011).

The MIG responded in a unimodal way to annual mean temperature $(P=0.002, d f=1.92)$ (Fig. $2 \mathrm{c})$, indicating that the disease intensity mediated by interactions of antagonistic species has a temperature optimum. The positive effect was detected for precipitation in the spring quarter $(P<2 \mathrm{E}-10, d f=1.00)$ (Fig. $2 \mathrm{~d})$, and the term partially accounted for the observed higher MIG values in southern Kyushu. This relationship between MIG and spring rainfall can be biologically interpreted as increased moisture on the forest floor, which could promote the maturation and subsequent release of ascospores of M. acanthopanacis. Sakamoto (1994) reported that the number of released M. acanthopanacis ascospores from the ascomata rapidly increased after rainfall events during the spring period. Aside from adaptation to local environments in both antagonistic species, the results obtained here suggest that both temperature and precipitation components partly explain large-scale variation of the disease intensity. However, it should be noted that our data is based on observations of just a single year, and so, we cannot fully ex- 
clude the possibility that the spatial pattern of MIG might change with time due to regional climate variation.

The spatial trend term showed a latitudinal cline from southern to northern Japan along the archipelago $(P<2 \mathrm{E}-$ $16, d f=3.90$ ) (Fig. 2e). Given that the GAM model successfully evaluated the effects of local and climatic factors that influence MIG, we attempted to determine what might cause this latitudinal cline. It was hypothesized that this might be due to a combination of limited distributions of resistance genotypes of host plant, and infection and/or virulence genotypes of parasitic fungi, which can lead to spatial mosaic of disease intensity across the host range. Resistance genotypes or genetic diversity of resistant genes in host plant species are known to show geographic mosaic-like patterns, and sometimes, latitudinal clines in geographic host ranges (e.g., Springer 2007, Caicedo 2008). A phylogeographic study of K. septemlobus using nuclear microsatellite markers showed the presence of multiple lineages and significant isolation by distance pattern in Japan (Sakaguchi et al. 2011, 2012), which indicates that gene flow via seed and pollen dispersal is insufficient to obscure the geographic population structure. Their finding could support the geographically limited distribution of host resistance genotypes in the archipelago, provided the species has a genetic basis for resistance against M. acanthopanacis. The distribution of K. septemlobus is suggested to have been influenced by geographically differentiated effects of climate changes during the Quaternary (Sakaguchi et al. 2010, 2011). During the last glacial maximum, large and continuous population ranges are thought to have been maintained only in central and southwestern part of Japan, while Hokkaido and the inland mountainous areas of northern Honshu were inferred to have harbored inhospitable climatic conditions for this species. If this is the case, long-term species association (i.e., greater exposure opportunity to selection pressure from the fungus) may have occurred in southern parts of the archipelago, which possibly led to removal of highly susceptible individuals, and thus, increased resistance of genotypes in these areas. On the other hand, population stochasticity, involving population bottlenecks and drifts may have influenced the distribution of resistance genotypes in the course of post-glacial range expansion of $K$. septemlobus into the northern territories during the Holocene. Such historical range expansion of host plant species is suggested to have shaped the latitudinal cline in genetic diversity of resistance gene homologs in Solanum pimpinellifolium populations (Solanaceae) (Caicedo 2008). Furthermore, if there is any genetic cost in maintaining resistant genes, genotypes without disease resistance might have been selectively favored during range expansion, which in turn resulted in a greater rate of growth and fecundity. On the other hand, there is currently no information on dispersal ability and geographic variation in the infection and virulence of $M . a c$ anthopanacis. However, the population genetic structure is suggestive of a restricted gene flow due to limited spore dispersal in Mycosphaerella species (Hayden et al. 2003, 2005, El Chartouni et al. 2011). Thus, if there exist multiple infection and/or virulence genotypes of M. acanthopanacis with restricted geographic distributions within the Japanese Archipelago, these could promote local adaptation of co-evolving antagonists, leading to spatial the mosaic of resistance across the host range (Burdon and Thrall 2000, Thompson 2005).

Overall, this study described a large scale spatial bias in the leaf disease intensity of $K$. septemlobus, and presented a possible latitudinal cline in intensity by considering the influences of local and regional factors involved in disease infection and prevalence processes. However, it is still largely unknown what factor(s) generated the latitudinal cline from the data we currently have. To fully understand the spatial bias in leaf disease intensity, and to test the hypotheses proposed here, further research should take account of cross-inoculation experiments using multiple samples of both host and parasite species as well as assessment of the genetic basis involving the disease intensity in the future.

\section{ACKNOWLEDGMENTS}

The authors would like to thank K. Niiyama, M. Shibata, K. Hoshizaki, S. Goto, S. Masutani, Y. Matsuki, R. Goda, C. Sumiyoshi, S. Higa, Y. Matsuura, Y. Azuma, Y. Isshiki and T. Toyama for their diligent assistance in the field survey, and Y. Takeuchi for her insightful discussion on this study. We are grateful to J. Worth for his comments, which significantly improved this manuscript.

\section{LITERATURE CITED}

Burdon JJ, Chilvers GA. 1982. Host density as a factor in plant disease ecology. Annu Rev Phytopathol 20: 143-166.

Burdon JJ, Thrall PH. 2000. Coevolution at multiple spatial scales: Linum marginale-Melampsora lini-from the individual to the species. Evol Ecol 14: 261-281.

Caicedo AL. 2008. Geographic diversity cline of R gene homologs in wild populations of Solanum pimpinellifo- 
lium (Solanaceae). Am J Bot 95: 393-398.

El Chartouni L, Tisserant B, Siah A, Duyme F, Leducq JB, Deweer C, Fichter-Roisin C, Sanssené J, Durand R, Halama P, Reignault P. 2011. Genetic diversity and population structure in French populations of Mycosphaerella graminicola. Mycologia 103: 764-774.

Fujimori N. 2007. Mechanisms of population maintenance in sparsely distributed species, Kalopanax pictus. $\mathrm{PhD}$ Dissertation. Kyoto University, Kyoto, Japan.

Fujimori N, Samejima H, Kenta T, Ichie T, Shibata M, Iida S, Nakashizuka T. 2006. Reproductive success and distance to conspecific adults in the sparsely distributed tree Kalopanax pictus. J Plant Res 119: 195-203.

Gilbert GS. 2002. Evolutionary ecology of plant diseases in natural ecosystems. Annu Rev Phytopathol 40: 13-43.

Gilbert GS, Hubbell SP, Foster RB. 1994. Density and distance-to-adult effects of a canker disease of trees in a moist tropical forest. Oecologia 98: 100-108.

Hayden HL, Carlier J, Aitken EAB. 2003. Genetic structure of Mycosphaerella fijiensis populations from Australia, Papua New Guinea and the Pacific Islands. Plant Pathol 52: 703-712.

Hayden HL, Carlier J, Aitken EAB. 2005. The genetic structure of Australian populations of Mycosphaerella musicola suggests restricted gene flow at the continental scale. Phytopathology 95: 489-498.

Holdenrieder O, Pautasso M, Weisberg PJ, Lonsdale D. 2004. Tree diseases and landscape processes: the challenge of landscape pathology. Trends Ecol Evol 19: 446-452.

Ito K. 1973. Jubyo-gaku Taikei II. Norin-syuppan, Tokyo. (in Japanese)

Manel S, Schwartz MK, Luikart G, Taberlet P. 2003. Landscape genetics: combining landscape ecology and population genetics. Trends Ecol Evol 18: 189-197.

McLaughlin JA. 2001. Distribution, hosts, and site relationships of Armillaria spp. in central and southern Ontario. Can J For Res 31: 1481-1490.

Moore SM, Borer ET. 2012. The influence of host diversity and composition on epidemiological patterns at multiple spatial scales. Ecology 93: 1095-1105.

Nossov DR, Hollingsworth TN, Ruess RW, Kielland K. 2011. Development of Alnus tenuifolia stands on an Alaskan floodplain: patterns of recruitment, disease and succession. J Ecol 99: 621-633.

Ohashi H 1994. Nomenclature of Kalopanax septemlobus
(Thunb. ex Murray) Koidzumi and classification of its infraspecific taxa (Araliaceae). J Jpn Bot 69: 28-31.

Ohba H. 1999. Family Araliacecae. In: Flora of Japan, IIc (Iwatsuki K, Boufford DE, Ohba H, eds). Kodan-sha, Tokyo, pp 259-267.

Osono T, Mori A, Koide K. 2004. Defoliation of giant dogwood (Swida controversa) caused by zonate leaf blight. Appl For Sci 13: 161-164.

R Development Core Team. 2010. R version 2.12.0: A Language and Environment for Statistical Computing. $\mathrm{R}$ Development Core Team, Vienna.

Sakaguchi S, Qiu YX, Liu YH, Qi XS, Kim SH, Han J, Takeuchi Y, Worth JRP, Yamasaki M, Sakurai S, Isagi Y. 2012. Climate oscillation during the Quaternary associated with landscape heterogeneity promoted allopatric lineage divergence of a temperate tree Kalopanax septemlobus (Araliaceae) in East Asia. Mol Ecol 21: 3823-3838.

Sakaguchi S, Sakurai S, Yamasaki M, Isagi Y. 2010. How did the exposed seafloor function in postglacial northward range expansion of Kalopanax septemlobus? Evidence from ecological niche modelling. Ecol Res 25: 1183-1195.

Sakaguchi S, Takeuchi Y, Yamasaki M, Sakurai S, Isagi Y. 2011. Lineage admixture during postglacial range expansion is responsible for the increased gene diversity of Kalopanax septemlobus in a recently colonised territory. Heredity (Ednib) 107: 338-348.

Sakamoto Y. 1994. Life history of Mycosphaerella acanthopanacis causing the brown leaf spot of Kalopanax pictus. Trans Mtg Hokkaido Br Jpn For Soc 42: 123-125.

Springer YP. 2007. Clinal resistance structure and pathogen local adaptation in a serpentine flax-flax rust interaction. Evolution 61: 1812-1822.

Thompson J. 2005. The Geographic Mosaic of Coevolution. The University of Chicago Press, Chicago and London.

Wood S. 2010. GAMs with GCV/AIC/REML smoothness estimation and GAMMs by PQL. http://cran.r-project.org/ package=mgcv. Accessed 2012 Mar 1 .

Xiang Q, Lowry PP. 2007. Flora of China. Vol. 13. Science Press, Beijing and Missouri Botanical Garden Press, St. Louis, p 441.

Yamazaki M, Iwamoto S, Seiwa K. 2009. Distance- and density-dependent seedling mortality caused by several diseases in eight tree species co-occurring in a temperate forest. Plant Ecol 201: 181-196. 


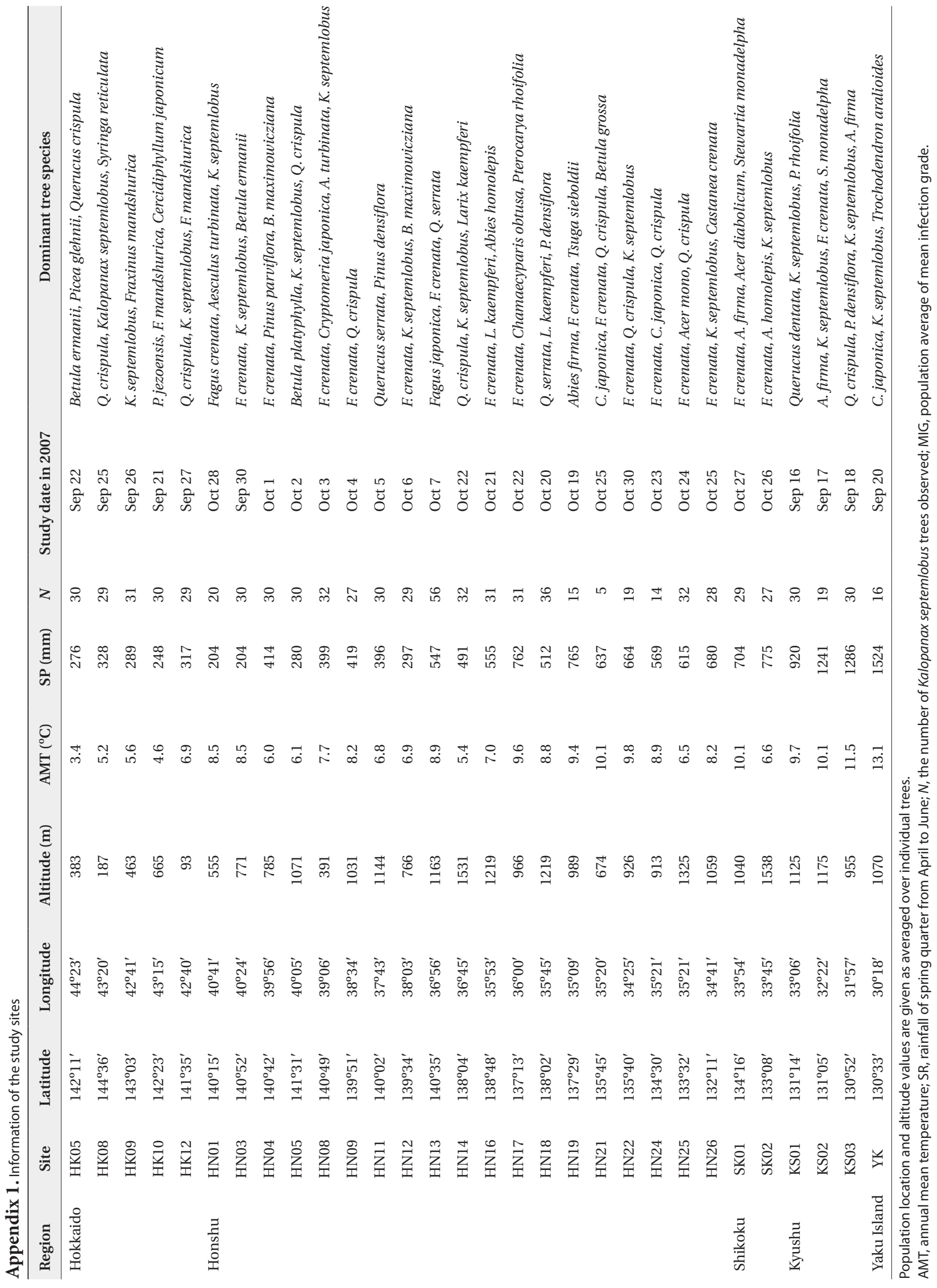

